\title{
A cooperação e/ou a colaboração no Espaço de Aprendizagem Digital da matemática
}

\author{
Aline Silva De Bona - vivaexatas@yahoo.com.br \\ Marcus Vinicius de Azevedo Basso - mbasso@ufrgs.br \\ Léa da Cruz Fagundes - leafagun@ufrgs.br
}

\begin{abstract}
Resumo: Nesse trabalho apresentamos os resultados parciais da pesquisa-ação de doutorado na qual conceituamos espaço de aprendizagem digital para a matemática valendo-se de elementos fundamentais para a aprendizagem como a cooperação e a colaboração no processo de cada estudante e do grupo ao qual o estudante pertence. A pesquisa está ancorada na Epistemologia Genética e nos Estudos Sociológicos de Piaget e nos conceitos freireanos de autonomia e diálogo e espaço virtual de Peters. O texto aborda as questões envolvendo a necessidade de se aprender a aprender matemática e a necessidade de se contextualizar de forma interdisciplinar a matemática nas tecnologias digitais. A cooperação e a colaboração presentes no espaço de aprendizagem digital da matemática, apontadas pelos estudantes do IFRS - Campus Osório em 2011, evidenciam que aprender a aprender matemática é importante, cotidiano e divertido e que a matemática está presente em todo o lugar.
\end{abstract}

Palavras-Chaves: Espaço de Aprendizagem Digital; Cooperação; Colaboração; Aprender a Aprender Matemática; Tecnologias Digitais

\section{The cooperation and / or collaboration in the Digital Learning Space of mathematics}

Abstract: In this paper presents the partial results of action research doctorate in which we conceptualize space of mathematics learning to taking advantage of key elements to learning how cooperation and collaboration in the process of each student and group to which the student belongs. The research is anchored in Genetic Epistemology and Piaget's Sociological Studies and the concepts of autonomy and freirean virtual space of dialogue and Peters. The paper deals with issues involving the need to learn how to learn mathematics and the need to contextualise mathematics in an interdisciplinary way in digital technologies. The present cooperation and collaboration within digital learning mathematics, students pointed out by IFRS - Campus Osorio in 2011, show that learning to learn mathematics is important, everyday and fun and that mathematics is present everywhere.

Key-Words: Digital Learning Space, Cooperation, Collaboration, Learning to Learn Mathematics; Digital Technologies

\section{Introdução}

Atualmente cada vez mais estão presentes na vida escolar de qualquer estudante as tecnologias digitais em rede, seja para entretenimento ou como forma de comunicação ou pesquisa. Exemplos disso podem ir desde uma simples consulta ao GoogleMaps para achar um endereço ou a busca por uma informação específica como "o que faz uma mitocôndria", ou ainda, "qual a finalidade de diferenciar uma função do tipo polinomial e do tipo exponencial". Tendo presente que a escola não pode desperdiçar este atrativo aos estudantes e valendo-se de uma busca permanente de "mobilizar" os estudantes a aprender a aprender matemática, estamos investigando sobre os diferentes espaços de aprendizagem digital. Durante nossa investigação, nos deparamos com os processos de cooperação e a colaboração, presentes em diversos momentos de estudo e resolução de problemas por estudantes, de maneira individual, ou por grupo de estudantes. Chamounos atenção que tais processos ocorrem independentemente da presença de professor $e$ consideramos relevante diferenciar e apontar se nestes processos se percebe uma aprendizagem de matemática via a escrita dos estudantes e/ou diálogos dispostos neste espaço. Ademais, tais processos poderiam ser analisados e verificados por uma professora - pesquisadora em diferentes momentos, questionando os estudantes no sentido de obter alguma verificação sobre a compreensão que os estudantes apresentaram nesses momentos específicos e envolvendo o tema matemático tratado? Os 
estudantes que participam desta pesquisa-ação são do ensino médio técnico integrado em informática, em torno de 60, duas turmas, no IFRS - Campus Osório, em 2011, na disciplina de matemática. Em paralelo a professora - pesquisadora realiza uma revisão de literatura sobre os processos identificados e demonstrados pelos estudantes como formas interessantes de aprender a aprender matemática como a cooperação e a colaboração. Noutra dimensão desta pesquisa, o espaço de aprendizagem digital é programado e qualificado por um grupo de estudantes destas turmas e de outros estudantes de 2009 e 2010 que já finalizaram o ensino médio em outras instituições de ensino e tendo como professora uma das autoras desse trabalho. Esses últimos permanecem envolvidos com o projeto no sentido de cada vez mais viabilizar uma melhor forma de mobilizar outros estudantes a aprender a aprender matemática.

O artigo está organizado da seguinte forma: na introdução demonstramos o processo da pesquisa e a equipe da mesma, na seção 2 conceituamos espaço de aprendizagem digital da matemática e suas caracterizações, na seção, conceituamos cooperação e colaboração como elementos importantes para a aprendizagem de matemática demonstradas neste espaço de aprendizagem digital, na seção 4 apresentamos as análises parciais via metacognição da aprendizagem de matemática, e na seção 5 tecemos as considerações finais.

\section{Espaço de Aprendizagem Digital da matemática}

O espaço de aprendizagem digital já passou por três fases de construção, sendo elas: a primeira idealizada pela professora-pesquisadora de forma teórica, depois feita a proposta de trabalho com portfólios de matemática cada vez mais baseados nas tecnologias digitais os estudantes antigos como descritos na introdução idealizaram a construção de um "lugar" virtual que denominaram de sala de aula virtual, e a fase atual dos estudantes antigos e novos trabalhando juntos com a denominação de espaço de aprendizagem digital com a ação da professora - pesquisadora em paralelo sempre dialogando com os estudantes sobre a matemática e a forma como aprendem é o interesse. $\mathrm{O}$ ambiente informatizado destinado à aprendizagem passa a ser denominado de "espaço de aprendizagem" quando se trata de vários ambientes em rede, para Peters (2009, p. 127), pois em exemplos, contempla hipertexto, comunicação virtual, mídias, e outras multimídias. Este espaço é denominado pelos estudantes da pesquisa-ação qualitativa em 2011 como: Espaço de Aprendizagem digital devido à justificativa de que "as aulas de matemática neste ambiente informatizado são semi-virtuais pela presença da prof. real e dos colegas, mas em casa e no tempo de pesquisa com os colegas da turma e de outras turmas ele é virtual, então: fizemos uma pesquisa com os colegas na forma de debate e votação sobre o nome que daríamos ao nosso espaço de aprendizagem se virtual ou digital e $97 \%$ de 60 presentes votaram no digital, e como a professora disse que temos de nos identificar e assim nos apropriar do que estamos aprendendo, defendemos este nome, ok, prof.? Ah, antes que eu esqueça, os 2 colegas que optaram por virtual foram pelo motivo: 'é mais interessante virtual' apenas, mas em fundamentação convincente".

Assim, esta pesquisa de tese em fase inicial, tem como objetivo conceituar/criar um "espaço de aprendizagem digital", conforme Peters (2009), em que todos os estudantes possam aprender a aprender matemática de acordo com Papert (1994, p.19). A pesquisa contempla o desafio de construir a proposta de ensino na modalidade presencial e a distância com práticas pedagógicas de matemática que permitam obter evidências sobre o processo de aprendizagem de cada estudante.

Destaca-se que o espaço de aprendizagem usado na escola atualmente ainda é hoje apenas a: sala de aula, o laboratório, a biblioteca, e outros ambientes particulares de cada instituição de ensino, que são possíveis de encontrar objetos de trabalho físicos, no entanto com o espaço virtual da internet disponível se faz necessário pensar num 'espaço de aprendizagem virtual', onde os objetos de trabalho são imaginários e inclusive não reais. Tal espaço tem muitas definições e pesquisas em diversas áreas, como exemplos, Fróes (2000), Cedro (2004), Peters (2009) e outros estudiosos que conceitual indiretamente como Lévy (1996) e Papert (1994), que denomina como micro-mundos de acordo com a evolução da tecnologia digital da época. Adotam-se as características da 
conceituação de Peters (2009): ausência de limites via internet, ausência de disposição espacial em muitos momentos, opacidade (criação de conceitos espaciais - simulação -, associados ao espaço real, e a possibilidade de relações entre objetos neste espaço), virtualidade (que é a representação digital de algo que é real), e a telepresença (presença não física do professor, estudantes e demais agentes do processo). Ainda colabora com esta ideia de espaço Morin (2000, p.11) quando afirma que a missão da educação, ou melhor do ensino, não é apenas transmitir saber, "mas uma cultura que permita compreender nossa condição e nos ajude a viver, e que favoreça, ao mesmo tempo, um modo de pensar aberto e livre". No entanto, o ser humano tem a tendência de reduzir tudo ao que é simples, assim como a sociedade também afasta tudo o que é complicado, segundo Morin (2000), no entanto para despertar o desejo de aprender no estudante inserido na sociedade se faz necessário reformar o pensamento, além de interligar os conhecimentos, vale-se da ação do estudante no seu processo de aprendizagem e explorar os recursos que são atrativos aos mesmos. Em pesquisa anterior, Bona e Basso (2010) revelaram que as tecnologias digitais são recursos atrativos aos estudantes e também que é um contexto para a matemática. Assim, o espaço de aprendizagem digital é um espelho do fenômeno complexo da sala de aula de hoje, muito heterogêneo, e que abriga uma diversidade de ânimos, culturas, classes sociais e econômicas, sentimentos, e outros elementos apontados ainda por Morin (2000). Desta reflexão se pensar em espaço de aprendizagem digital como físico ou virtual, ou ainda ambos?

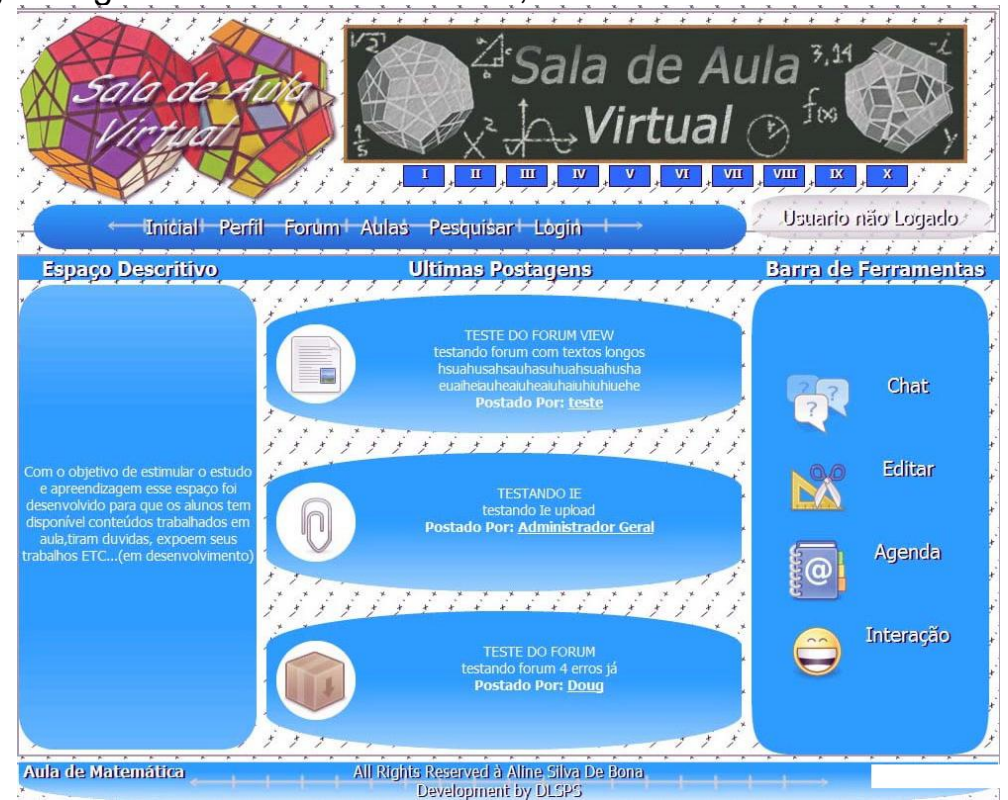

Figura 1: Primeira ideia do Espaço de Aprendizagem Digital que era Sala de Aula Virtual

Então, o espaço de aprendizagem virtual é um local não situado geograficamente onde o processo de ensino-aprendizagem ocorre através da organização e aplicação de uma concepção pedagógica, baseada na comunicação, interação, trabalho colaborativo do professor com os estudantes, e cooperativos dos estudantes entre si e com o professor. Porém, existem espaços virtuais que não são de aprendizagem, para Peters (2009), o espaço virtual destinado à educação deve ter funções tecnológicas voltadas para os aspectos pedagógicos, onde da interação das tecnologias de computador, multimídia e rede, surgem tecnologias especiais para comunicação, transmissão, exibição, busca, acesso, análise, armazenamento, realidade virtual e gerenciamento. Juntas, resultam em unidades de diferentes configurações com uma eficiência nunca vistas até então. Para este espaço virtual ser de aprendizagem a concepção pedagógica do professor deve estar alicerçada no diálogo, assim para Freire (1996, p.31), "o professor que pensa certo deixa transparecer aos educandos que uma das bonitezas de nossa maneira de estar no mundo e com o mundo, como seres históricos, é a capacidade de, intervindo no mundo, conhecer o mundo". Ainda, Freire (1996, p. 66), "o respeito à autonomia e à dignidade de cada um é um imperativo ético e não um favor que podemos ou não conceder uns aos outros". Relacionando as duas citações de Freire se entende que a prática docente requer como 
saber a valorização da autonomia do estudante em aprender a aprender o seu mundo, não de forma passiva, mas pró-ativa segundo a citação: "A capacidade de aprender, não apenas para nos adaptar, mas, sobretudo para transformar a realidade, para nela intervir, recriando-a, fala da nossa educabilidade a um nível distinto do nível de adestramento dos outros animais ou do cultivo de plantas" (FREIRE, 1996, p.76). È fundamental destacar a denominação dada pelos estudantes dentro deste espaço de aprendizagem digital como Interação (sala de aula), como demonstra a figura 2. Neste local os estudantes postam atividades feitas individualmente ou em grupo, participam do fórum e, segundo expressão de um estudante, "chamam" um chat para trabalhos coletivos. Ainda aponta-se que as atribuições da professora - pesquisadora e a de todos os estudantes é a mesma para postar, interagir, abrir fóruns e chats, ou seja, o espaço é de todos, onde todos tem as mesmas liberdades, direitos e os deveres são variados, ou seja, segundo a fala dos estudantes:

- um estudante de 15 anos: ".... a prof. aprende a entender como a gente pensa e resolver as contas antes de dar errado, dai quando responde, sempre com uma pergunta, ela faz a gente pensar no erro, dai na resposta já nos ligamos...dai ela não aprende igual a nos alunos, pois ela já sabe a matemática....."

- outro de 16 anos: "A gente tenta descobrir e conhecer a matemática, enquanto a prof. fica mostrando as ideias de como a gente pode usar a matemática na vida, dai fica mais legal noEsp@Di (sigla criada por esta turma) já que a gente monstra para a prof. a matemática digital dos recursos e ela tenta entender também o que a gente faz nas contas, então tem uma troca, e também não é somente certo e errado, pois no fórum dá para perguntar e se esquece olha de novo depois, assim como nos exercícios posso fazer com os colegas antes da sora chegar online e quando ela chega ela vi tudo o que fizemos, entende melhor como pensamos e nos ajudamos também quando ela quer postar coisas e não sabe como tipo um vídeo pesado...é um aprender de cada um diferente....."

- mais um estudante de 15 anos: "bah é muito estranho com a prof. usa o computador mas é trio jeito que ela lê os exercícios da gente parece que ela quer advinha como pensamos, e faz muita pergunta, impossível colar as atividades, e ver as postagens dos colegas também é muito bom para quando o cara tá perdido, e também penso que a prova fica tão fácil depois de tudo que fizemos na sala de aula digital...tipo entender aquele video do you tube e achar a função foi muito difícil dai fazer um problema de compras que é juro simples foi fácil....Ah e como diz a sora: as vezes entender a postagem do colega é um aprendizado para despertar a tua forma de resolver o problema....todos aprendemos mas depende de cada um também pois o espaço tá online todo tempo...e a prof. lota de coisas diferentes além dos colegas que também podem postar coisas diferentes como o Jogo Mais Difícil do Mundo que era só geometria plana e velocidade de contorno...."

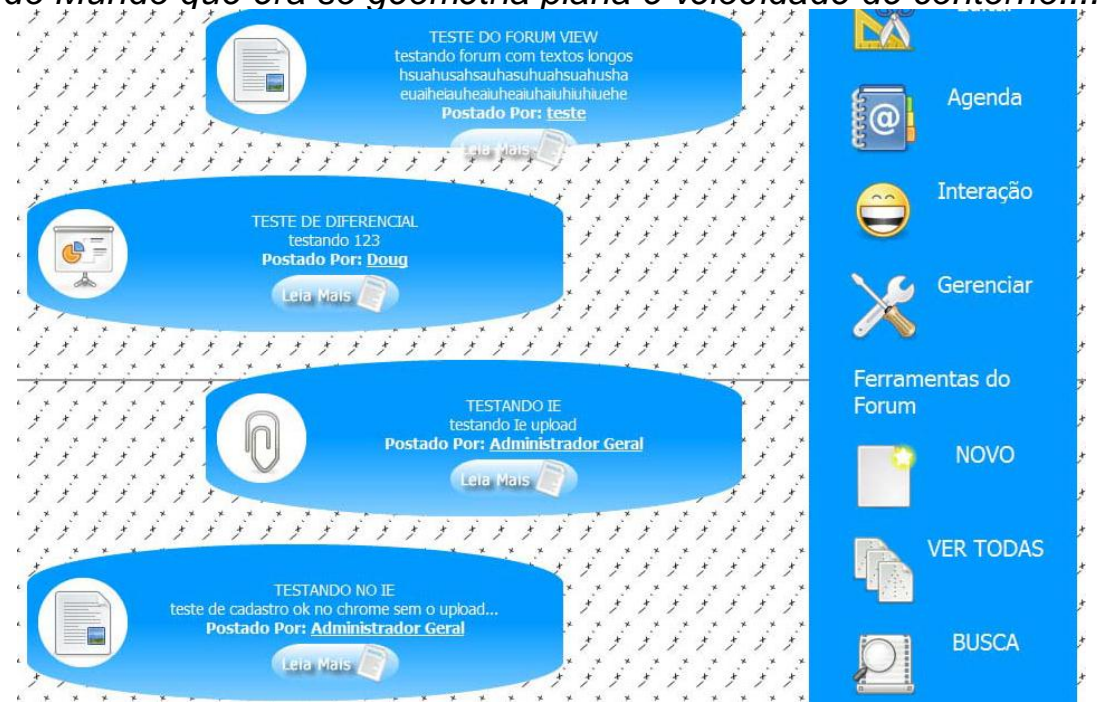

Figura 2 - Interação no Espaço de Aprendizagem Digital da matemática

Outro elemento muito importante é a questão afetiva demonstrada pelos estudantes na construção do espaço de aprendizagem digital no qual eles colocam fotos, frases, pensamentos do dia, links de musica e outras atividades que são interessantes a 
estes no espaço da aula de matemática, "como se fossem conversas paralelas na aula real", segundo um estudante de 16 anos, "apenas no Esp@Di não atrapalha em nada a aula, nem desrespeita a professora e os colegas e a gente se diverte e interage como em redes sociais". Essa dimensão é corroborada por Fagundes, Sato e Maçada, 1999, p.20.

"O educador não deve pensar apenas na área cognitiva, em um ambiente de aprendizagem construtivista é preciso ativar mais do que o intelecto. Ao educador cabe a função de ativação da aprendizagem, ele deve trabalhar consigo mesmo a percepção do seu próprio valor e promover a auto-estima e a alegria de conviver e cooperar, bem como desenvolver um clima de respeito e auto-respeito"

Assim, torna-se importante focar o processo de aprendizagem, para além da instrução ou transmissão de conteúdos, observando que hoje é mais relevante o como se sabe do que o que e o quanto se sabe. Desta forma, aprender é saber realizar, fazer, construir, agir; e conhecer é compreender as relações, é atribuir significado às coisas, levando em conta não apenas o atual e o explícito, mas também o passado, o possível e o implícito, real ou virtual. Nessa perspectiva, o aprender a aprender traduz a capacidade de refletir, analisar e tomar consciência do que se sabe, dispor-se a mudar os próprios conceitos, buscar novas informações, substituir velhas "verdades" por teorias transitórias, adquirir novos conhecimentos resultantes da rápida evolução da ciência e da tecnologia e de suas influências sobre o desenvolvimento da humanidade. É com esta finalidade de aprender a aprender que se faz necessário práticas docentes centradas na ação dos estudantes que se conceitua o espaço de aprendizagem digital da matemática, sempre norteado pelo diálogo entre os agentes envolvidos em qualquer processo de aprendizagem, no caso da escola: professores, pais, colegas da turma e de outras turmas e séries, além outros profissionais da área da educação.

\section{A cooperação e a colaboração no processo de aprendizagem de matemática}

Neste espaço de aprendizagem digital muitas questões referentes à prática docente são observadas além das estratégias metacognitivas adotadas pelos estudantes no processo de aprender a aprender matemática, e também na forma como cada estudante explora os recursos digitais da tecnologia disponibilizados na internet e os propostos pelos colegas e professora - pesquisadora. Mas destaca-se como resultado parcial desta pesquisa - ação a necessidade de se "explicar" os elementos cooperação e colaboração no que tange a epistemologia genética de Piaget, pois é esta teoria que sustenta a conceituação de aprendizagem proposta neste espaço de aprendizagem digital. É comum se encontrar definições como: a) cooperação é a comunicação isolada de cada um em busca de resolver um problema, e colaboração é quando cada um se comunica de forma cooperativa para finalizar o problema, segundo Roschelle \& Teasley (1995); b) colaboração é entendida como a comunicação entre pessoas que trabalham juntas e com um mesmo objetivo, e cooperação é a comunicação em que não existe mais o conceito de individuo, apenas o de grupo, segundo o artigo de Bair (1989); cooperação é um nível intermediário de compartilhamento das atividades em comunidades virtuais, com discussão temática e estabelecimento de normas de trabalho coletivo no intuito de realizar uma tarefa, enquanto que a colaboração compreenderia a construção de conhecimentos com objetivos estabelecidos e compartilhados com os participantes desta comunidade virtual, sendo superior o nível de relação social, segundo Campos (2003). No entanto, tais definições são inversas como a) e c) no sentido de que o grau mais elevado é a cooperação, ou incompletas como b) frente as conceituações de Piaget. Para Piaget (1973, p.105), "cooperar na ação é operar em comum, isto é, ajustar por meio de novas operações (qualitativas ou métricas) de correspondência, reciprocidade ou complementariedade, as operações executadas por cada um dos parceiros. (...)", e "colaborar, entretanto, resume-se à reunião das ações que são realizadas isoladamente pelos parceiros, mesmo quando o fazem na direção de um objetivo" (1973, p. 81). Ainda, Piaget (1973), destaca que cooperar constitui um sistema de operações que se permitem ajustar umas às outras operações, e estas operações individuais constituem um sistema de ações descentradas e podem ser coordenadas devido aos agrupamentos de operações de outros, como se fossem próprias. Entende-se o ser humano como um ser social, assim sua inteligência se desenvolve por meio das suas interações sociais, ou seja, das suas 
ações sociais, e como Piaget aponta que a socialização da inteligência inicia-se já com a aquisição da linguagem, antes da fase sensória-motora, isso significa que a cooperação está presente em todo o processo de desenvolvimento do homem. Assim, para Piaget (1973; 1998), cooperação é um método construído na reciprocidade entre os indivíduos, que ocorre pela descentração intelectual, havendo a construção não apenas de normas morais, mas também racionais, tendo a razão como produto coletivo. Então, se conceituaria segundo Piaget (1973): colaboração como uma interação com trocas de pensamento sem ocorrer operações racionais, onde o pensamento pode ser: via comunicação verbal, por coordenações de ponto de vistas e discussões, por exemplos, e, desta forma, a colaboração é anterior a cooperação em trocas sociais; e a cooperação como uma interação que requer a formação de vínculos e de reciprocidade afetiva entre os sujeitos do processo de aprendizagem, onde estas interações são as interindividuais, que possibilitam a modificação do sujeito na sua estrutura cognitiva e do grupo como um todo, como um sistema de interações, e não somente somativa, assim ocorrer a construção do conhecimento.

O espaço de aprendizagem digital demonstra, observando a ação dos estudantes, que os mesmos se valem da interação - cooperação e colaboração - para aprender a aprender matemática, ou seja, os estudantes fazem uso da cooperação para solucionar problemas cognitivos de forma qualitativa. No entanto, cabe apontar que a cooperação não ocorre quando não há o respeito mútuo e a reciprocidade entre os estudantes que estão interagindo, sendo estes dois elementos fundamentais para a autonomia de cada estudante, segundo Freire (1999), no sentido de que esta é sempre solidária ao grupo. Então, a cooperação é um processo de aprendizagem criador de realidades novas, de novas perspectivas sobre um assunto de matemática, por exemplo, e não apenas um meio de trocas entre os estudantes. Este processo é potencializado pelas tecnologias digitais como em atividades sincrônicas e assincrônicas, exemplos, de chat e fórum, respectivamente demonstradas pela palavra interação (que contempla as duas ações) nas figuras 1 e 2 do espaço de aprendizagem digital. Destaca-se que a metodologia de pesquisa denominada pesquisa-ação, que é adotada nesta pesquisa, é uma das modalidades de pesquisa colaborativa, segundo Zeichner (1993) ainda com outras tipificações, mas é importante apontar que quando se trata de metodologia de pesquisa se refere a uma técnica, e quando se trata da proposta de Piaget se faz menção à aprendizagem. Assim, colaboração na metodologia de pesquisa se refere ao trabalho coletivo onde cada agente do processo faz atividades em prol do coletivo, mesmo cada um com seus objetivos específicos, e todos têm um objetivo comum compartilhado.

\section{Análises parciais via metacognição da aprendizagem de matemática}

A metacognição é o conhecimento que o estudante possui sobre o seu próprio conhecimento, e em paralelo, para Piaget (1977), se traduziria como abstração reflexionante contraposta à abstração empírica, que se apoiava sobre os objetos físicos e materiais da própria ação; neste caso, na verdade, não há a pura apreensão dos sentidos, intervindo, efetivamente, nos esquemas conceituais elaborados pelo sujeito. A abstração reflexionante aponta um salto qualitativo, quando se apresenta como a tomada de consciência pelo sujeito - a reflexão sobre reflexão. Os Parâmetros Curriculares Nacionais (BRASIL, 1999, PCN e PCN+) são orientações aos professores de Escola Básica sobre as habilidades e competências de matemática que cada estudante deve ter o direito de aprender na escola, valendo de todos os recursos disponíveis atualmente assim como todos os estudos sobre a educação para a escola ser um lugar potencializador de saberes sob as diferentes áreas do conhecimento. Desta forma, acreditando que quando se trabalha com questões desafios e problemas, ou projetos de aprendizagem, ou simples atividades propostas aos estudantes mas de forma interessante é curiosa, ou como pesquisas, não há como limitar os conceitos de matemática e/ou conteúdos que serão tratados, pois foge da alçada do professor o que o estudante irá pensar e que estratégias metacognitivas irá usar para solucionar a atividades, e ainda mais num espaço de aprendizagem digital cooperativa onde os estudantes tem múltiplas possibilidades entre todos, ficando assim os PCN a melhor forma de viabilizar cada vez mais o aprender a aprender matemática a cada estudante valendo-se da sua complexa e pessoal realidade, 
segundo Morin (2000). Destaca-se ainda que o foco não é o conteúdo em si mas o uso que o estudante faz deste conteúdo.

O conhecimento lógico-matemático, segundo Piaget (1978), é uma construção que resulta da ação mental da criança sobre o mundo, construído a partir de relações que a criança elabora na sua atividade de pensar o mundo, e também das ações sobre os objetos. Ainda, conforme Piaget (1973), o papel inicial das ações e das experiências lógico-matemáticas concretas exige preparação para chegar ao desenvolvimento do espírito dedutivo, e isto por duas razões:

1) é que as operações mentais ou intelectuais que intervêm nestas deduções derivam justamente das ações interiorizadas, quando esta interiorização, juntamente com as coordenações que supõem são suficientes, as experiências lógico-matemáticas enquanto ações materiais resultam já inúteis e a dedução interior basta a si mesmo;

2) é que a coordenação de ações e as experiências lógico-matemáticas dão lugar, ao interiorizar-se, a um tipo particular de abstração que corresponde precisamente a abstração reflexionante.

As evidências demonstradas pelos estudantes no espaço de aprendizagem dig ital são muitas de cooperação observada via metacognição, no entanto, apenas para evidenciar transcreve-se uma situação que foi proposto por um estudante aos colegas fora da aula presencial e num espaço livre do estudante, postado como doc, o seguinte problemas: "Uma empresa fabrica bolsas e sapatos e vende cada um respectivamente por 45 e 58 reais, onde seu custo fixo é de $40 \%$ do preço de cada vendida. E o custo variável da bolsa é de 25 para cada 3 unidades, e o do sapato é de 8 reais cada até 100 unidades vendidas, e de 6 reais para mais unidades vendidas. Encontre a função lucro desta empresa e faça seu gráfico". A turma tem 30 estudantes e destes 27 participaram da discussão, que ocorreu inicialmente no texto do colega, cada qual escrevia de uma cor, até que um estudante abriu um fórum para esta questão e convidou a professora para participar, e paralelamente foram feitos 12 chat entre grupos variados. Para fins de organização do artigo, a transcrição ocorre de forma sistemática mas com apenas as "falas" fundamentais, e o recorte feito com 5 estudantes denominados por A (foi o que propôs a questão), B, C (foi o que abriu um fórum de discussão), D e E (participou de 5 chats dos 7 que ocorreram até a resolução correta da questão).

B: "Eu não sei...parece fácil quando se lê mas na hora de colocar no papel é difícil....vou colocar o que pensei.... Bolsa: $L B(x)=45 x-20,6-(25 / 3) x$ e o Sapato: $L S(x)=$ $58 x-20,6-8 x, x<100$, e $-6 x, x>100$. A função é polinomial do primeiro grau dai é reta, mas fazer junto não consegui no graphmatica...."

C: "humm...levei um tempão para achar os 20,6 ...to devagar, mas para conferir é $45+58=103$ dai $40 \%$ que dá 41,2 sendo metade de cada tipo de produto....??? Porque metade?"

Observa-se nas interações anteriores a ação de cooperação entre os estudantes no momento que o C deseja compreender o que B fez para partir deste ponto já conquistado, sendo uma operação segundo Piaget (1973), outro exemplo de operação de correspondência é a noção de domínio dada a variável dos sapatos.

A: “...esqueci de dizer que este exercício não é de matemática mas da disciplina de administração 1...os desafios para pesquisas....não dá para fazer apenas resposta do caso de 8 bolsas e 6 sapatos pois a sora vai querer que a gente explique o caso geral....e ela monstra para a sora de matemática então não dá para enrolar...."

C: "Tá legal o que fez $B$, eu também pensei nessa linha...apenas se juntar e arrumar semelhantes fica mais fácil rascunhar gráfico e lembra que sora disse que não dá para fazer recorrência no graphmatica, dai tem de ser geogebra...olha: $L(x)=45 x-20,6$ $(25 / 3) x+58 x-20,6-8 x=103 x-41,2-49 / 3 x=260 / 3 x-41,2$ para $x$ menor ou igual a 100 (você esqueceu do igual), e se $x>100$ fica $103 x-41,2-43 / 3 x=266 x / 3-41,2$, dá uma diferença de $6 / 3=2 x$ de uma para outra ne? Ah só vou tentar fazer gráfico se alguém confirmar nossa conta....alguém pedir ajuda para a sora de matemática?"

$\mathrm{A}$ interação de $\mathrm{A}$ e $\mathrm{C}$ acima demonstra a familiaridade com os recursos digitais gráficos - softwares como geogebra e graphmatica, além disso a contextualização dada a matemática na aula de administração, e as outras relações matemáticas estabelecidas. Ainda o diálogo com a professora de matemática pois esta postagem é de acesso da 
mesma, sendo uma relação boa e sem medo da "autoridade" errônea dada a matemática, com a cultura do medo, sendo um aspecto afetivo negativo. Ainda outro exemplo de operação de complementaridade, segundo Piaget (1973), é a inserção da condição menor e IGUAL dada pela observação do colega.

D: "quem é o $x$ ? Bolsas ou sapatos?...tinha entendido $B$ mas $C$ misturo tudo...seria as unidades vendidas, mas não pode fazer isso...."

A: "...é verdade C....o $D$ tem razão....."

C: "ainda bem que estamos fazendo junto....vi o que vocês falaram...tá certo....., voltamos para o $B$, mas arrumamos cada uma...."

Nas três interações acima destaca-se a afetividade dos estudantes entre si no espaço de aprendizagem digital e a necessidade de estudaram juntos, sendo este um fator importante presente na vida dos estudantes em qualquer idade: a socialização.

$\mathrm{E}$ : "...fica assim: $x$ é o numero de bolsas, e y é o numero de sapatos

$L(x)=45 x-20,6-(25 / 3) x=110 x / 3-20,6 ; L(y)=58 y-20,6-8 y=50 y-20,6$ se $y$ for menor ou igual a 100, e se y maior que 100 dá $L(y)=58 y-20,6-6 y=52$ y-20,6. Agora é só fazer as duas retas combinadas em qualquer software pois terá de explicar ambos gráficos....vou tentar...."

A: "...tá errado quem disse que o custo fixo é metade de cada produto???"

O desenvolvimento das interações em especial da tomada de consciência da estudante A acima demonstra uma operação de reciprocidade para Piaget (1973), além da já destaca anteriormente que pode-se fazer separado o lucro do sapato e da bolsa porque o da empresa será apenas a soma de ambos.

D: "bah é mesmo....então terá de ficar tudo junto....e com duas variáveis....hum..a prof. de mat. Nunca deu assim para a gente fazer....e agora??"

B: "sem pânico vamos tentar a sora tem de ser a ultima opção mesmo a gente vendo ela logada....ela tá deixando a gente pensar...."

Observando a postagem acima do estudante B o mesmo entende que a professora é como sua colega no espaço de aprendizagem digital e também percebe que a professora deixa os estudantes pesquisarem e interagirem entre si antes de dar ideias de resolução, ou sair apontando erros não é seu perfil. E os estudante acalmam-se uns aos outros com incentivos afetivos para não desistir de aprender a resolver o problema em questão.

A: " gostei das letras de $E$ então juntamos como $C$ fez....L $(x+y)=110 x / 3-20,6+$ $50 y-20,6=110 x / 3+50 y-41,2$, se $y \quad \square \square \square \square \square$ e $L(x+y)=110 x / 3+52 y-41,2$, se $y>100 . "$

C: “...eu acho que agora está correto, então temos de fazer o gráfico e eu acho que não faria sozinho.... ah antes tem de lembrar que x e y são no minimo zero, dai a empresa tem prejuízo de 100, que é o fixo.... mas pela produção não tem logica nada produzir então $x$ e y são ambos maiores que zero."

$\mathrm{E}$ : “....e continuando $C$ são $N$, pois não existe $1 / 2$ da bolsa e nem sapato negativo...."

O estudante C destaca que "não faria sozinho", ou seja, aponta a necessidade de um trabalho coletivo e além disso cooperativo para aprender a aprender matemática. Nas interações acima novamente observa-se operações qualitativas e métricas segundo Piaget (1973).

A: “...são 3 variáveis então é 3D....xiiiiii...só o winplot ou uma de cada vez....apenas função preço menos custo variáveis e a lucro ser condicionada devido ao custo fixo.....tipo: $P C V(x)=110 x / 3$ e PCV $(y)=50 y$ se y $\square \square \square \square \square$ ou $P C V(y)=52 y$ se $y>100$

$L(x+y)=P C V(x)+P V C(y)-41,2 \ldots$ bah a sora de matemática vai adorar....."

Prof.: "Já adorei...está ficando ótimo....o trabalho em grupo está funcionando muito bem....parabéns....mas ainda falta o gráfico.....e algumas ideias a serem pensadas $e$ interpretadas sobre o custo fixo...."

Depois de dois dias de muitas postagens e perguntas na escola na saída a aula ocorreram novas postagens.

D: "Colegas...uaua...pensei muito, pesquisei livros e também alguns exercícios que fizemos nas olimpíadas de matemática online, lembram?...e acho que dá para fazer assim....

Bolsas $-L(x)=45 x-0,4.45 x-25 x / 3=76 x / 3$ e Sapatos $-L(y)=58 y-0,40.58 . y-8 y=$ 
$26,85 y$, se $y \square \square \square \square$ e $L(y)=58 y-0,40.58 . y-6 y=24,85$, se $y>$

$\square \square E u$ acho que está bem mais fácil a estratégia que você usou e nos estamos equacionando mais complicado tudo junto... vou plotar....junto e separado.....

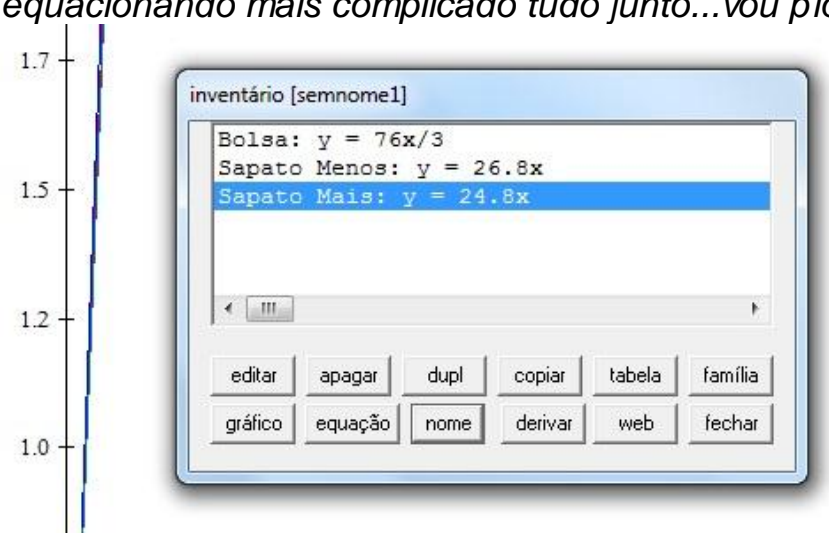

Figura 3- Gráfico do estudante B
C: " ...os coeficiente angulares são muito próximos e a bolsa fica entre os sapatos de menos de 100 e mais de 100 ...dai teríamos de pensar será que sempre a bolsa é mais lucrativa que os sapatos quando menos de 100, e menos quando os sapatos mais de 100? Fico feliz de entender e usar a matemática..."

A: "sim, eu também, amigo C, são funções de grau 1 e crescimento permanente $e$ as funções não se cruzam para trocar..."

B: “...olhem em 3D para menos de 100: $z$ (aprox.) $=25,3 x+26,8$ y....muito legal...levo horas estudando e textando...minha mãe até briga que não vou jantar....heheh

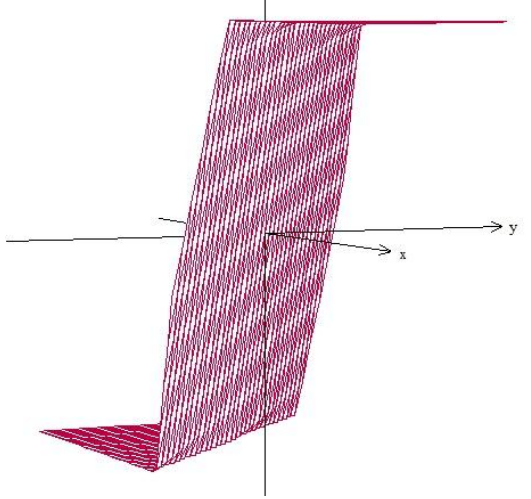

....a função lucro irá sempre crescer quanto mais vendo mais ganho, e também é complicado fazer nos softwares pois até 100 seria uma coisa e depois outro....fiz a mão e parece que ficou pior...pois considerei que as quantidades variassem diferente, dai eu penso que: só fica gráfico linear se sempre vendermos igual quantidade, se não fica muitas combinações.... mas conversei com a prof. de administração e ela disse que isso é matéria de superior e que quer que a gente

Figura 4 - Gráfico do estudante $B$

Prof.: "Muito boas ideias até agora pessoal...parabéns...acharam os equívocos de interpretação e também de matemática, e a prof. de administração tem razão, porém vocês já compreenderam o mais importante que são os conceitos envolvidos...."

No espaço de aprendizagem digital se desenvolveu este problema até o fim, com muitas interações (não sendo necessário neste artigo para a compreensão do que se objetiva), e inclusive foi feita uma apresentação na aula de administração baseada em Print Screen do fórum, sendo um sucesso a explicação dos estudantes segundo a professora da área técnica.

As ações de cooperação denominadas por Piaget (1973) como operações de correspondência, reciprocidade ou de complementaridade são muitos e apontadas sob diferentes processos de aprendizagem de cada sujeitos, acima apenas destacamos algumas para demonstrar os resultados de colaboração e cooperação na aprendizagem dos estudante proporcionado no espaço de aprendizagem digital viabilizado pela complexidade e diversidade potencializado pelas tecnologias digitais de hoje. Cada reflexão é uma nova forma de pensamento e permite a tomada de consciência complexa que cabe a cada ser humano, segundo Piaget (1977). É importante destacar a alegria dos estudantes em estar aprendendo matemática, a autonomia e desejo de resolver as questões seja pesquisando em diferentes fontes e recursos como livros e professores, seja consultando os colegas, a dedicação dos estudantes ao participarem do fórum e das demais atividades, demonstrando responsabilidade sobre seu processo de aprendizagem de matemática, seja ele em aula de ou em outras disciplinas.

\section{Considerações Finais}

As diferenciações dadas aos termos cooperação e colaboração se fazem necessária no âmbito de pesquisa na área de Informática na Educação, seja em 
matemática, ou em qualquer área do conhecimento, devido ao fato simples de que segundo Morin (2000) a complexidade surge do que parece senso comum ou vivenciado cotidianamente sem tomada de consciência. Na perspectiva de Piaget, a construção do conhecimento somente ocorrerá se os estudantes cooperarem, e a colaboração refere-se à troca de informações entre os sujeitos envolvidos no processo de aprendizagem, com a conotação de ato solidário, ou seja, cada um faz a sua parte para um conjunto beneficiado. Assim, o que diferencia o uso dos recursos tecnológicos digitais na área da educação matemática não são estes, mas o que os professores podem propor através destes. $\mathrm{E}$ mais, como é o caso do espaço de aprendizagem digital da matemática é um recurso computacional online construídos pelos estudantes de forma multidisciplinar numa ação cooperativa na sua maioria e em outros momentos de forma colaborativa quando se trata especialmente da relação dialogada com a professora sobre a matemática, pois no que tange ao manejo dos recursos digitais já é cooperativo para ambos.

O espaço de aprendizagem digital é um conceito novo e complexo, porém muito atrativo e dinâmico aos estudantes que incorporam seu uso para aprender a aprender matemática de forma tão natural, como nativos digitais que são. Finalmente, observamos que é cada vez mais necessário apontar que o currículo escolar não "cabe" no "micromundo construído por cada estudante na escola e, em especial, neste espaço de aprendizagem digital. A pesquisa com este espaço de aprendizagem digital está em andamento num permanente trabalho de pesquisa ora colaborativo, ora cooperativo com os estudantes, com a finalidade de demonstrar que aprender a aprender matemática pode e deve ser alegre, importante para a vida do próprio estudante

\section{Referências}

BAIR, J. Supporting Cooperative Work with Computers: addressing the meeting mania. Artigo de 1989. Disponível: http://blog.kutova.com/2006/10/09/colaboracao-x-cooperacao/. Acesso em 13.jul.201

BARDIN, L. Análise de conteúdo. Lisboa: Edições 70, Ltda, 1977.

BRASIL. Ministério da Educação. Secretaria de Educação e Cultura. Parâmetros Curriculares Nacionais: ensino médio. Brasília: MEC/SEMTEC, 4v., 1999.

CAMPOS M. Comunidades em rede: da publicação à construção de conhecimentos. In: Maraschin C, Freitas L, Carvalho D. Psicologia \& Educação. Porto Alegre: UFRGS; 2003.

CEDRO, W.L. O espaço de aprendizagem e a atividade de ensino: o clube de matemática. USP. Dissertação de mestrado. http://www.teses.usp.br, Julho, 2004.

FAGUNDES, L.; MAÇADA, D. L.; SATO, L. S. Aprendizes do futuro: as inovações começaram. Brasília: MEC, 1999.

FREIRE, P. Pedagogia da Autonomia: saberes necessários à prática educativa. 22ª ed.São Paulo:Paz e Terra, 1996.

FRÓES BURNHAM, T. Sociedade da informação, sociedade do conhecimento, sociedade da aprendizagem: implicações ético-políticas no limiar do século. In: LUBISCO, N.; BRANDÃO, L. (Org.) Informação e informática. Salvador: Edufba, 2000. p. 283 - 307, 2000.

LÉVY, P. O que é virtual. São Paulo: Editora 34, 1996.

MORIN, E. A cabeça bem-feita: repensar a reforma, reformar o pensamento. Rio de Janeiro: Bertrand Brasil, 2000.

PAPERT, S. A Máquina das crianças. Porto Alegre: Artmed, 1994.

PIAGET, J. Estudos Sociológicos. Rio de Janeiro: Forense, 1973.

A Equilibração das Estruturas Cognitiva. Problema central do desenvolvimento. Trad.

Álvaro Cabral. Rio de Janeiro: Zahar, 1976.

Abstração Reflexionante: Relações lógico-aritméticas e ordem das relações espaciais.

Porto Alegre: Artmed, 1977.

Sobre a pedagogia. São Paulo: Casa do Pscicólogo, 1998.

Epistemologia Genética. São Paulo: Martins Fontes, 2002.

$\overline{1978 .}$.

Psicologia e Epistemologia: Por uma teoria do Conhecimento. Rio de Janeiro: Forense,

PETERS, O. A educação à distância em transição. São Leopoldo: Unisinos, 2009.

ROCHELLE, J.; TEASLEY, S.D. Construction of shared knowlwdge in collaborative problem solving. In: C. O'Malley (Ed.), Computer-supported collaborative learning. New York: SpringerVerlag, 1995.

ZEICHNER, K. El maestro como profesional reflexivo. In: Cuadernos de pedagogía, v. 220, p. 
44-49. 1993.

V. $9 \mathrm{~N}^{\mathrm{o}}$ 2, dezembro, 2011 